\title{
Correction to: preserving prion strain identity upon replication of prions in vitro using recombinant prion protein
}

Natallia Makarava ${ }^{1,2}$, Regina Savtchenko ${ }^{1,2}$, Peter Lasch ${ }^{3}$, Michael Beekes ${ }^{3}$ and Ilia V Baskakov ${ }^{1,2^{*}}$

\section{Correction}

Figure 6 of the original publication [1] contained an error in the Wavenumber in panels $B$ and $C$. The wavenumbers $1616(\mathrm{Cm}-1)$ in panels $B$ and $C$ should have been $1516(\mathrm{~cm}-1)$. The updated figure has been published in this correction article; the original article has been updated.

\section{Author details \\ ${ }^{1}$ Center for Biomedical Engineering and Technology, University of Maryland School of Medicine, 111 S. Penn St, Baltimore, MD 21201, USA. ²Department of Anatomy and Neurobiology, University of Maryland School of Medicine, Baltimore, MD, USA. ${ }^{3}$ Centre for Biological Threats and Special Pathogens, Robert Koch-Institute, 13353 Berlin, Germany.}

Received: 12 September 2018 Accepted: 18 September 2018

Published online: 24 September 2018

\section{Reference}

1. Makarava N, Savtchenko R, Lasch P et al (2018) acta neuropathol commun 6(92). https://doi.org/10.1186/s40478-018-0597-y

\footnotetext{
* Correspondence: Baskakov@som.umaryland.edu

${ }^{1}$ Center for Biomedical Engineering and Technology, University of Maryland School of Medicine, 111 S. Penn St, Baltimore, MD 21201, USA

${ }^{2}$ Department of Anatomy and Neurobiology, University of Maryland School

of Medicine, Baltimore, MD, USA
} 


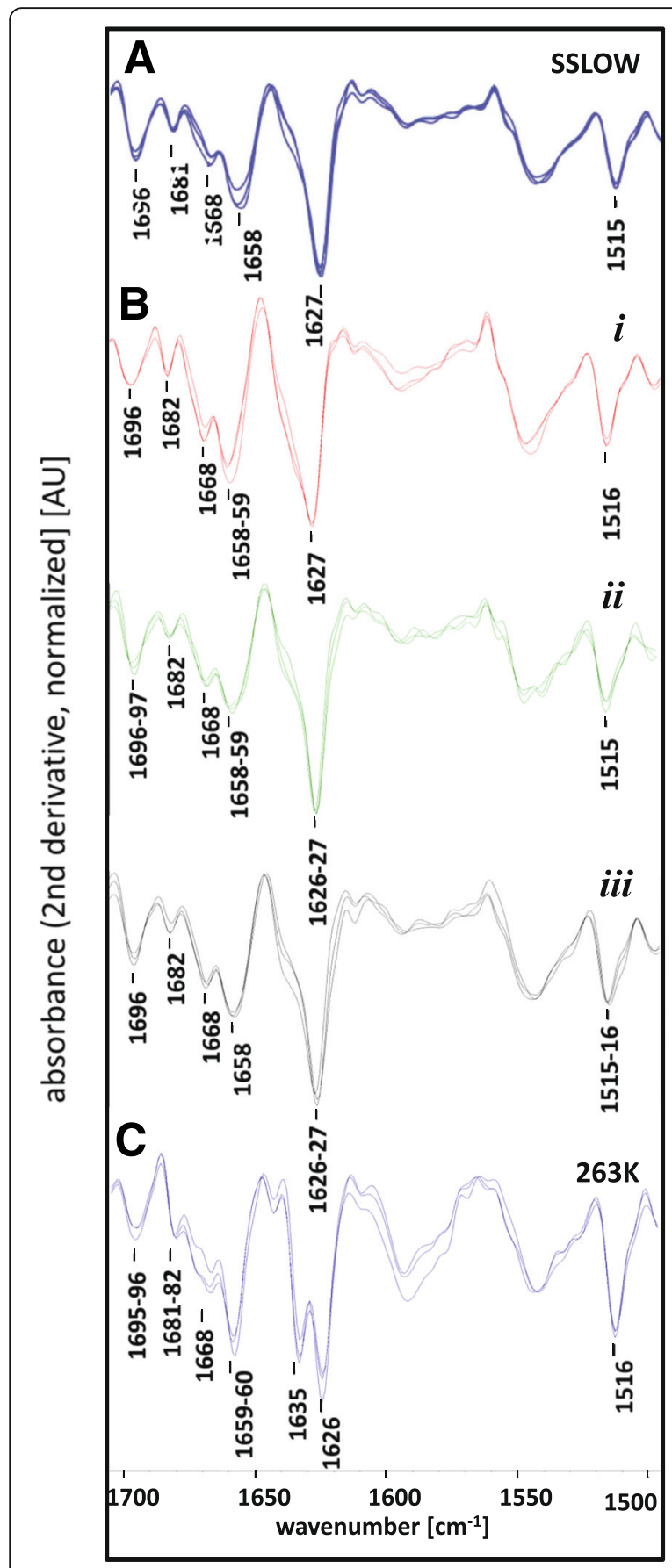

Fig. 6 Corrected version of Fig. 6. The wavenumbers in panels B and C have been updated. The wavenumbers in panel $A$ remain the same 